\title{
What works where in prevention of Covid-19: The case of Somalia
}

Abdi Gele ${ }^{1}$

${ }^{1}$ Norwegian Institute of Public Health, Oslo, Norway. (Correspondence to: Abdi Gele: Abdi.Gele@fhi.no).

Citation: Gele A. What works where in prevention of Covid-19: The case of Somalia. East Mediterr Health J. 2020;26(5):495-496. https://doi. org/10.26719/2020.26.5.495

Received: 14/03/20; accepted: 21/04/20

Copyright (c) World Health Organization (WHO) 2020. Open Access. Some rights reserved. This work is available under the CC BY-NC-SA 3.0 IGO license (https://creativecommons.org/licenses/by-nc-sa/3.o/igo).

The outbreak of coronavirus disease 2019 (COVID-19) has posed significant challenge to the countries with the best health systems in the world (1). As governments scramble to contain and/or prepare for outbreaks of the COVID-19 virus, there is increasing concern about the potential impact of the coronavirus epidemic in countries with weak health systems (2). The World Health Organization (WHO) encourages governments to improve preparation for and response to COVID-19, such as legislation and policy, coordination, surveillance, response preparation, risk communication, human resources, and laboratory capacities (2). So far, most of the COVID-19 cases are in countries with a decent health system, including China, South Korea, Italy, and the United States of America. The preventive measures that have stabilized the epidemic in China may also work in other strong economies and countries with solid health systems. However, how countries with weak health systems such as Somalia will cope, remains unclear.

Somalia is a country affected by complex emergencies resulting from prolonged conflict, climate change, outbreaks of communicable diseases and a dysfunctional health system. Less than $30 \%$ of the Somali population have access to health services (3). The national health system is fragmented, and the absence of unified health system governance has affected the capacity of national authorities to implement coordinated interventions. Nonetheless, the COVID-19 epidemic requires a wellcoordinated preparation and response - a capacity that Somalia lacks. The WHO Somali office is the sole trusted partner that can initiate a coordinated plan throughout the country to prevent and contain the epidemic. However, the security situation in the country may limit the presence of WHO experts in the field, and the absence of epidemiologists and highly trained public health professionals may affect the success of WHO efforts.

The country's health system has no capacity to make early case detections, isolate and care for patients, and trace contacts. As a result, the sole alternative for the country is to develop effective preventive measures to mitigate the epidemic. Most countries rely on measures including social distancing, closure of schools, cancelling big social gatherings and improved hygiene (2). These measures depend largely on how individuals respond to the advice on prevention and this is highly unlikely to work in Somalia for several reasons. People in Somalia are not familiar with the notion 'health prevention'; they only seek health advices when they become ill (4). In addition, advice such as stay at home, or self-quarantine, will be an economic burden too heavy to bear for the majority of the population that depend their livelihood on daily paid jobs. Regarding cancellation of social events, mosques are where the biggest social gatherings occur several times a day. Cancelling such events and or advising against it may provide an opportunity for terror groups to exploit and use it against the government. This is exacerbated by prevalent religious fatalism; a belief that one's fate is predetermined and if they were to be infected by COVID-19, it was meant to happen regardless of their efforts. Prominent religious leaders, who consistently preach that COVID-19 is a punishment only for the unbelievers, enforce this perception. Those religious leaders have supreme power in shaping the mindset of the Somali community and the Somali government has little power and resources to enforce preventive actions or to challenge the misinformation created by religious leaders. Moreover, there are no research institutions in the country, nor human resources for research that help policy-makers decide the context specific mitigation activities.

In the midst of this swiftly evolving crisis and the current development in Kenya and Ethiopia, which have confirmed COVID-19 cases, certain contextual and culturally sensitive preventive measures may help Somalia and other similar settings prepare and effectively respond to the epidemic. Extensive information campaign about the preventive actions with risk communication has pivotal importance. To reinforce the guidelines given by the health authorities, the campaign should be delivered through mosques, and social and public media with clear presence of religious leaders in information provision. If the campaign is led by religious leaders it will have strong potential to encourage people to follow the preventive instructions for self-isolation, cancelling big events including religious gatherings, and also to adhere to hygiene practices as instructed. However, the correct information should be provided to religious leaders prior to their involvement in the awareness campaign. Hygienic kits should be supplied in large scale and should be made available in markets, schools and religious sites. WHO and other international actors may help surveillance, early case detection and isolation of infected individuals and management of the very sick, using WHO guidelines. There are large 
internally displaced populations (IDPs) in the country, living in camps with high population density, which is often coupled with unsanitary conditions. Mobilizing IDPs' community leaders and health providers to spread awareness on basic hygiene is critical to prevent the epidemic from this vulnerable group.

The existence of early warning surveillance systems, strong community-based surveillance under the polio programme, functioning federal and state health authorities offer an opportunity to an effective and successful national response. As the Somali federal government leads the national response to
COVID-19, regional authorities and the private health establishments should continue to work with the federal authorities and other health agencies (WHO, UNICEF and others) to ensure a collaborative response. To unite the country towards the prevention of the epidemic, the Federal Ministry of Health $(\mathrm{MoH})$ should take an apolitical role to avoid power struggles and rifts with the regional health ministries, which may otherwise impede the coordination efforts. Finally, political commitment is an essential component of the COVID-19 response. Therefore, to contain the epidemic, the highest level of political commitment and good leadership is needed more than ever in Somalia today.

\section{Acknowledgement}

I thank Dr Muna Elmi, Prof. Omar Maye and Prof. Khalif Bile for their constructive input in the paper.

\section{References}

1. M Anderson, Hans Heesterbeek, Don Klinkenberg, T Déirdre Hollingsworth: How will country-based mitigation measures influence the course of the COVID-19 epidemic? The Lancet. March 09.2020.

2. World Health Organization. Strategic preparedness and response plan. Geneva: World Health Organization; 2020 (https://www. who.int/publications-detail/strategic-preparedness-and-response-plan-for-the-new-coronavirus).

3. World Health Organization: Strategic review of the Somali health sector: challenges and prioritized actions. Report of the WHO mission to Somalia, 2015. (http://somaliangoconsortium.org/download/578571d68do8f/).

4. Gele AA, Pettersen KS, Kumar B, Torheim LE. Diabetes risk by length of residence among Somali women in Oslo area. J Diabetes Res. 2016;2016:5423405. 